\title{
Prevalence and Predisposing Factors of Suicidal Ideation Among the University Students in Bangladesh: A Single-Site Survey
}

\author{
Mohammed A. Mamun ${ }^{1,2} \cdot$ Istihak Rayhan ${ }^{3} \cdot$ Khaleda Akter $^{4} \cdot$ Mark D. Griffiths $^{5}$
}

Accepted: 19 September 2020 / Published online: 26 October 2020

(C) The Author(s) 2020

\begin{abstract}
Recently, suicide among Bangladeshi university students has become a serious problem. However, to date, there have been no studies assessing suicidal behaviors among Bangladeshi students. Therefore, the present study investigated suicidal ideation (SI) and its risk factors among this population. A classroom-based convenience sampling method was utilized to survey 665 students of a university in Bangladesh $(67.5 \%$ males; aged 21.16 years: $\mathrm{SD} \pm 1.6$ ). In addition to socio-demographic questions, the survey also included the Smartphone Application-Based Addiction Scale, Bergen Facebook Addiction Scale, and Depression Anxiety Stress Scale-21. Results showed that the prevalence of suicidal ideation was $2.3 \%$ in the past $24 \mathrm{~h}, 4.8 \%$ in the past 15 days, $6.9 \%$ in the past month, $14.7 \%$ in the past year, and $61.1 \%$ in the lifetime. The unadjusted regression model showed that being divorced (or separated) from a partner $(\mathrm{OR}=4.486,95 \% \mathrm{CI}=$ $1.972-10.207, p<0.0001)$, Facebook addiction $(\mathrm{OR}=1.550,95 \% \mathrm{CI}=1.006-2.388, p=$ $0.047)$, depression $(\mathrm{OR}=1.657,95 \% \mathrm{CI}=1.677-4.211, p<0.0001)$, anxiety $(\mathrm{OR}=$ $2.649,95 \% \mathrm{CI}=1.624-4.320, p<0.0001)$, and stress $(\mathrm{OR}=2.626,95 \% \mathrm{CI}=1.673-$ $4.122, p<0.0001)$ were the risk factors of past-year SI. Compared with global prevalence rates, the present study reported higher levels of SI prevalence. Therefore, supportive suicide prevention programs are needed to tackle SI and alongside comorbid psychopathology.
\end{abstract}

Keywords Suicidal ideation · Psychopathology $\cdot$ Facebook addiction · Depression · Anxiety Stress $\cdot$ Bangladeshi students

Suicidal behaviors are complex life-threatening phenomena that can adversely affect individuals' health and can have consequences for the emotional state of families and the community (Eaton et al. 2011). Suicidal phenomena can comprise various degrees and types of suicidal ideation, suicidal attempts, and actual suicide occurrences (Klonsky et al. 2016). The

Mark D. Griffiths

mark.griffiths@ntu.ac.uk

Extended author information available on the last page of the article 
relationship between these phenomena and vulnerable populations is of great relevance to clinicians in their attempts to identify those at highest risk of suicide (Bebbington et al. 2010; Klonsky et al. 2016).

Suicide and suicidal behaviors are closely related and the associated risk factors can be divided into two major groups (i.e., distal [predisposing] factors and proximal [precipitating] factors) (Blasco et al. 2019; Klonsky et al. 2016). Proximal risk factors are those factors that have a direct contributing role in suicidality such as hopelessness, depression, impaired memory specificity, and psychiatric disorders (e.g., bipolar disorders, anxiety disorders, stress-related disorders). Distal risk factors are predisposing risk factors that often contribute to and/or interplay with the aforementioned proximal factors (e.g., childhood adversities, interpersonal violence, bullying or dating violence in early life, parental psychopathology, parental death, family divorce and/or discord, epigenetic changes, and genetic influences) (Beautrais 2000; Blasco et al. 2019; Franklin et al. 2017; Turecki and Brent 2016). Additionally, recent studies have suggested problematic technology use (i.e., internet addiction, Facebook addiction, smartphone addiction) can also play direct and indirect roles in suicide and suicidal behaviors via associated behaviors such as emotional distress and sleep disturbance (Becker et al. 2004; Cheng et al. 2015; Guo et al. 2018; Jasso-Medrano and Lopez-Rosales 2018; Kim et al. 2019; Luxton et al. 2012; Mok et al. 2015; Wong et al. 2013).

As reported by the World Health Organization (WHO), approximately $80 \%$ of world suicides occur in low- and middle-income countries such as Bangladesh, where the present study was carried out (WHO 2019). The country has been reported to have approximately eight suicides per 100,000 people annually although the actual rate is believed to be higher than that reported rate because many Bangladeshi individuals would rather have the cases be classed as accidental deaths rather than suicide to avoid post-mortem complexities such as families not wanting to get the police involved and families not wanting the burial of the body to be delayed (Arafat 2019). This is reflected by recent retrospective studies among Bangladeshi student populations (Arafat and Mamun 2019; Griffiths et al. 2020; Mamun et al. 2020a, b; Mamun and Griffiths 2020a, b), and by Feroz et al. (2012) who claimed the suicide rate in Bangladesh was approximately 129 per 100,000 population (although this was a non-representative study carried out in a rural area).

Moreover, utilizing suicide press reports Shah et al. (2017) suggested that individuals aged below 30 years comprise $61 \%$ of total suicide cases reported cases in Bangladesh. Arguably, many of these are likely to be students. However, it should be noted that the mass media may selectively report specific suicides more than others, including youth suicides which are considered to be more newsworthy. Additionally, Bangladesh still lacks any kind of epidemiological study concerning suicidal behaviors among students (i.e., suicidal ideation, plans, attempts), although suicidality among the general population has been examined in a few studies (e.g., Arafat et al. 2018; Begum et al. 2017; Feroz et al. 2012; Salam et al. 2017). Consequently, there is a large knowledge gap because Bangladeshi student suicides are a neglected topic by researchers, health policymakers, and the medical profession (Arafat 2019; Mashreky et al. 2013). Therefore, the present study examines suicidal ideation among Bangladeshi students particularly because adequate benchmark data concerning suicidal behaviors and its associated risk factors among this cohort are needed to help develop and implement effective suicide prevention programs. 


\section{Methods}

\section{Participants and Procedure}

The present cross-sectional convenience sample "paper and pencil" survey study was conducted in the English language among the students of Bangabandhu Sheikh Mujibur Rahman Science and Technology University (Gopalganj, Bangladesh). The study involved students who were present in the classroom and who were willing to participate in the study during survey administration (March to April 2019). A total of 913 participants were eligible to take part during the survey period, of which 682 participated. Of these, 665 completed the whole survey $(67.5 \%$ males; $21.16 \pm 1.6$ years) following the removal of incomplete questionnaires (response rate $=72.9 \%$ ).

\section{Ethics}

Formal clearance to carry out the study was obtained from the ethics committee of the Institute of Allergy and Clinical Immunology of Bangladesh [Reference ID: IRBIACIB/CEC/ 07201919/301] and signed permission from the respective authorities of the participants' departments prior to the survey. Participants were also informed that all their data would be kept anonymous and confidential, and all of them were provided with information about the study nature and purpose, the procedure, and the right to withdraw their data. Before being able to access the questions, the detailed procedure of the study, rights of participation, data security, and confidentiality were provided according to the Helsinki Declaration 1975.

\section{Instruments}

Socio-demographic Variables The socio-demographic variables assessed included age, gender, permanent residence, relationship status, socio-economic status, year of academic study, smoking status, and the regular daily exercise. For family socio-economic status, income less than 15,000 BDT was categorized as lower income, 15,000 to 30,000 BDT as middle income, and more than 30,000 BDT for upper income (Begum et al. 2017; Rafi et al. 2019). Participants were asked if they were cigarette smokers by utilizing a dichotomous response (i.e., yes/no). Exercise status was assessed by asking participants if they engaged in at least 30 min of moderate daily physical activities that resulted in an increase in breathing or heart rate (based on the procedure of Mamun and Griffiths 2019a).

Suicidal Ideation To assess suicidal ideation, participants were asked if they had ever thought about suicide during specific time periods, i.e., the past day, past 15 days, past month, past year, and lifetime (Jahan et al. 2020; McKinnon et al. 2016; Peltzer et al. 2017).

Depression, Anxiety, and Stress The Depression Anxiety and Stress Scale-21 (DASS-21; Lovibond and Lovibond 1995) assesses depression (e.g., "I couldn't seem to experience any positive feeling at all"), anxiety (e.g., "I was worried about situations in which I might panic and make a fool of myself"), and stress (e.g., "I felt that I was using a lot of nervous energy"). The scale comprises 21 items that provides scores based on three 7-item subscales with each item rated on a 4-point scale $(0=$ did not apply to me at all to $3=$ applied to me very much or most of the time). Original scores are multiplied by two for a final score, and a severity rating 
index was used to define levels of depression (0-9 normal, 10-13 mild, 14-20 moderate, 2127 severe, and 28+ extremely severe), anxiety (0-7 normal, 8-9 mild, 10-14 moderate, 15-19 severe, and 20+ extremely severe), and stress (0-14 normal, 15-18 mild, 19-25 moderate, 2633 severe, and 34+ extremely severe. Acceptable internal consistency was obtained previously for the subscales (Mamun et al. 2019a, b; Rafi et al. 2019). For example, Cronbach's alphas for the depression, anxiety, and stress subscales were $0.77,0.78$, and 0.83 , and the overall Cronbach's $\alpha$ was 0.91 (Mamun et al. 2019b). In the present study, Cronbach's alphas for the depression, anxiety, and stress subscales were good $(0.78,0.75$, and 0.74 , respectively) and Cronbach's $\alpha$ for the overall scale was very good (0.89).

Smartphone Addiction Smartphone addiction was assessed using the six-item Smartphone Application-Based Addiction Scale (SABAS; Csibi et al. 2018). The scale uses a 6-point scale to rate each item ( $1=$ strongly disagree to $6=$ strongly agree $)$ and includes such items as "My smartphone is the most important thing in my life" and "Conflicts have arisen between me and my family (or friends) because of my smartphone use." The higher the score, the higher the risk of developing an addiction to smartphone applications. Good psychometric properties and internal scale consistency have been found previously (Chen et al. 2019; Lin et al. 2019). Cronbach's alpha in the present study was good (0.72).

Facebook Addiction The six-item Bergen Facebook Addiction Scale (BFAS; Andreassen et al. 2012) was used to assess the risk of Facebook addiction. BFAS items are assessed using a 5 -point scale $(1=$ very rarely and $5=$ very often $)$ and includes such items as "How often in the last year have you spent a lot of time thinking about Facebook or planned use of Facebook?" and "How often in the last year have you used Facebook in order to forget about personal problems?" The scores range from 6 to 30 and a higher score suggests a higher risk of being addicted to Facebook. Good psychometric properties and internal scale consistency have been found previously (Chen et al. 2019; Mamun and Griffiths 2019a). Cronbach's alpha in the present study was very good (0.80).

\section{Statistical Analysis}

Statistical Package for Social Science (SPSS) version 22.0 and Microsoft Excel 2016 were used for the statistical analysis. First, the data were entered into Excel, and then prepared for input into the SPSS. Descriptive statistics (i.e., frequencies, percentages, mean values with standard deviations) were used to describe the data. Additionally, chisquare tests were calculated using SPSS. Chi-squares (for all variables) and binary regression tests (for the significant variables) were performed with past-year suicidal ideation as the dependent variable as has been done in previous studies (e.g., Blasco et al. 2019; Eskin et al. 2016). Based on the suggestive cutoff score, smartphone addiction was categorized if the participants scored a total 21 on the SABAS (out of 36; Lin et al. 2019), whereas those who scored 19 (out of 30) on the BFAS were categorized as being at risk of Facebook addiction (Bányai et al. 2017). Participants were categorized as being depressed, anxious, and/or stressed if they scored between moderate to extreme on each DASS-21 subscale. The results of logistic regression are reported as unadjusted and adjusted odds ratios with $95 \%$ confidence intervals. 


\section{Results}

The participants' socio-demographic information is presented in Table 1. Most of the participants were male (67.5\%), not in relationship (65.0\%), came from rural area (71.7\%), and were non-smokers (82.6\%) (Table 1). Approximately four-fifths of the participants reported to be at risk of smartphone addiction (78.8\%), 37.9\% at risk of Facebook addiction, 49.5\% depressed, $57.0 \%$ anxious, and $46.3 \%$ stressed. Results also showed the SI prevalence rates among participants to be $2.3 \%$ (past day), $4.8 \%$ (past 15 days), $6.9 \%$ (past month), $14.7 \%$ (past year), and $61.1 \%$ (lifetime) and there were no significant differences in all suicidal behaviors (except past year) and gender (Table 3).

Only relationship status was found to be associated significantly with past-year SI. More specifically, participants who had separated or divorced from their partner had a predominantly higher SI prevalence, whereas the second highest prevalence was reported among participants in a relationship $\left(\chi^{2}=34.705, \mathrm{df}=1, p<0.001\right)$ (Table 1$)$. In respect to psychopathology, Facebook addiction $\left(18.3 \%\right.$ vs. $\left.12.6 \% ; \chi^{2}=3.9951, \mathrm{df}=1, p=0.046\right)$, depression $(20.7 \%$ vs. $\left.8.9 \% ; \chi^{2}=18.234, \mathrm{df}=1, p<0.001\right)$, anxiety $\left(19.5 \%\right.$ vs. $8.4 \% ; \chi^{2}=16.080, \mathrm{df}=1$, $p<0.001)$, and stress $\left(21.1 \%\right.$ vs. $\left.9.2 \% ; \chi^{2}=18.510, \mathrm{df}=1, p<0.001\right)$ were all significantly associated with past-year SI. There was no association between past-year SI and smartphone addiction $\left(\chi^{2}=0.533, \mathrm{df}=1, p<0.457\right)$ (Table 2$)$.

A binary regression analysis was carried out to examine the associations between past-year SI and all the significant variables in bivariate analysis. The unadjusted model confirmed that being separated or divorced $(\mathrm{OR}=4.486 ; 95 \% \mathrm{CI}=1.972-10.207, p<0.001)$, addicted to

Table 1 Distribution of the socio-demographic variables with last year suicidal ideation

\begin{tabular}{|c|c|c|c|c|}
\hline Variables & Total; $n(\%)$ & Past-year suicidal ideation; $n(\%)$ & $\chi^{2}$ test value & $p$ value \\
\hline \multicolumn{5}{|l|}{ Gender } \\
\hline Male & 449 (67.5) & 60 (13.4) & \multirow[t]{2}{*}{2.076} & \multirow[t]{2}{*}{0.150} \\
\hline Female & $216(32.5)$ & $38(17.6)$ & & \\
\hline \multicolumn{5}{|l|}{ Year of study } \\
\hline 1 st year & $227(34.1)$ & $42(18.5)$ & \multirow{5}{*}{8.831} & \multirow{5}{*}{0.065} \\
\hline 2nd year & $166(25.0)$ & 28 (16.9) & & \\
\hline 3 rd year & 109 (16.4) & $9(8.3)$ & & \\
\hline 4 th year & $118(17.7)$ & $12(10.2)$ & & \\
\hline Masters & $43(6.5)$ & $6(14.0)$ & & \\
\hline \multicolumn{5}{|l|}{ Relationship status } \\
\hline Separated/divorced & $28(4.2)$ & $14(50.0)$ & \multirow{3}{*}{34.705} & \multirow[t]{3}{*}{$<0.001$} \\
\hline Single & $432(65.0)$ & 47 (10.9) & & \\
\hline In a relationship & $203(30.5)$ & $37(18.2)$ & & \\
\hline \multicolumn{5}{|l|}{ Permanent residence } \\
\hline Rural & 477 (71.7) & 66 (13.8) & \multirow{2}{*}{1.672} & \multirow[t]{2}{*}{0.196} \\
\hline Urban & $179(26.9)$ & $32(17.9)$ & & \\
\hline \multicolumn{5}{|c|}{ Family monthly income } \\
\hline Lower income & $231(34.7)$ & $32(13.9)$ & \multirow[t]{3}{*}{1.899} & \multirow[t]{3}{*}{0.387} \\
\hline Middle income & $186(28.0)$ & $23(12.4)$ & & \\
\hline Upper income & $217(32.6)$ & $37(17.1)$ & & \\
\hline \multicolumn{5}{|l|}{ Smoking status } \\
\hline Yes & $113(17.0)$ & $22(19.5)$ & \multirow[t]{2}{*}{2.352} & \multirow[t]{2}{*}{0.125} \\
\hline No & $549(82.6)$ & $76(13.8)$ & & \\
\hline \multicolumn{5}{|l|}{ Exercise status } \\
\hline Yes & $230(34.6)$ & $31(13.5)$ & \multirow{2}{*}{0.524} & \multirow{2}{*}{0.469} \\
\hline No & $430(64.7)$ & 67 (15.6) & & \\
\hline
\end{tabular}


Table 2 Distribution of the behavioral health variables with last year suicidal ideation

\begin{tabular}{|c|c|c|c|c|}
\hline Variables & Total; $n(\%)$ & Past-year suicidal ideation; $n(\%)$ & $\chi^{2}$ test value & $p$ value \\
\hline \multicolumn{5}{|c|}{ Smartphone addiction } \\
\hline Yes & $524(78.8)$ & $80(15.3)$ & \multirow[t]{2}{*}{0.553} & \multirow[t]{2}{*}{0.457} \\
\hline No & $141(21.2)$ & $18(12.8)$ & & \\
\hline \multicolumn{5}{|c|}{ Facebook addiction } \\
\hline Yes & $252(37.9)$ & $46(18.3)$ & \multirow[t]{2}{*}{3.9951} & \multirow[t]{2}{*}{0.046} \\
\hline No & $413(62.1)$ & $52(12.6)$ & & \\
\hline \multicolumn{5}{|l|}{ Depression } \\
\hline Yes & $329(49.5)$ & $68(20.7)$ & \multirow[t]{2}{*}{18.234} & \multirow[t]{2}{*}{$<0.001$} \\
\hline No & $336(50.5)$ & $30(8.9)$ & & \\
\hline \multicolumn{5}{|l|}{ Anxiety } \\
\hline Yes & $379(57.0)$ & $74(19.5)$ & \multirow[t]{2}{*}{16.080} & \multirow[t]{2}{*}{$<0.001$} \\
\hline No & $286(43.0)$ & $24(8.4)$ & & \\
\hline \multicolumn{5}{|l|}{ Stress } \\
\hline Yes & $308(46.3)$ & $65(21.1)$ & \multirow[t]{2}{*}{18.510} & \multirow[t]{2}{*}{$<0.001$} \\
\hline No & $357(53.7)$ & $33(9.2)$ & & \\
\hline
\end{tabular}

Facebook $(\mathrm{OR}=1.550 ; 95 \% \mathrm{CI}=1.006-2.388, p=0.047)$, depressed $(\mathrm{OR}=1.657 ; 95 \% \mathrm{CI}=$ $1.677-4.211, p<0.001)$, anxious $(\mathrm{OR}=2.649 ; 95 \% \mathrm{CI}=1.624-4.320, p<0.001)$, and stressed $(\mathrm{OR}=2.626 ; 95 \% \mathrm{CI}=1.673-4.122, p<0.001)$ were significantly associated with SI (Table 4).

\section{Discussion}

The present study examined suicidal ideation (SI) and associated risk factors among Bangladeshi students. Results showed the SI prevalence rates among participants to be $2.3 \%$ (past day), $4.8 \%$ (past 15 days), 6.9\% (past month), 14.7\% (past year), and 61.1\% (lifetime) (Table 3). To date, no previous study has ever examined SI prevalence among Bangladeshi university students, although one previous study among the adolescents reported a $5 \%$ lifetime SI (aged 14-19 years; Begum et al. 2017) which is much lower than the 61.1\% rate reported in the present study (but the present study included older participants).

Some of the participants in the study were teenagers, and compared with the global rates, a recent study (McKinnon et al. 2016) of adolescent past-year SI of 32 low- and middle-income countries (like Bangladesh) reported similar past-year SI prevalence (12.2 to 16.2\%) similar to the $14.7 \%$ past-year prevalence rate in this study. Another large-scale cross-national study reported the past-year SI prevalence as $11.7 \%$ across 12 nations' university students (i.e., Australia (15.9\%), China (7.1\%), Japan (9.5\%), Jordan (17.7\%), Iran (15\%), Italy (4.3\%), Palestine (16\%), Saudi Arabia (10\%), Turkey (8.8\%), Tunisia (8.5\%), UK (15.3\%), and USA $(10 \%)$ ), whereas the overall lifetime SI prevalence was reported to be $27.4 \%$ (i.e., Australia (47.6\%), China (21.8\%), Japan (25.9\%), Jordan (22\%), Iran (29.7\%), Italy (19.4\%), Palestine (22.2\%), Saudi Arabia (17.7\%), Turkey (24.2\%), Tunisia (20.9\%), UK (39.3\%), and USA $(31.4 \%)$ ) (Eskin et al. 2016). Again, these past-year SI rates are similar to that found in the present study. Additionally, another study reported a $12 \%$ lifetime SI prevalence among the university students of six Association of Southeast Asian Nations (ranging from 6.9 to $16.3 \%$; Peltzer et al. 2017) which was much lower than the $61.1 \%$ reported in the present study. A recent meta-analysis among college students (i.e., Mortier et al. 2018) suggested a similar 
Table 3 Distribution of suicidal ideation across gender

\begin{tabular}{|c|c|c|c|c|c|}
\hline \multirow[t]{2}{*}{ Variables } & \multirow[t]{2}{*}{ Total; $n(\%)$} & \multicolumn{2}{|l|}{ Gender } & \multirow[t]{2}{*}{$\chi^{2}$ test value } & \multirow[t]{2}{*}{$p$ value } \\
\hline & & Male; $n(\%)$ & Female; $n(\%)$ & & \\
\hline \multicolumn{6}{|c|}{ Suicidal ideation - past day } \\
\hline Yes & $15(2.3)$ & $11(2.4 \%)$ & $4(1.9 \%)$ & \multirow[t]{2}{*}{0.237} & \multirow[t]{2}{*}{0.627} \\
\hline No & $655(97.7)$ & $438(97.6 \%)$ & $212(98.1 \%)$ & & \\
\hline \multicolumn{6}{|c|}{ Suicidal ideation - past 15 days } \\
\hline Yes & $32(4.8)$ & $21(4.7 \%)$ & $11(5.1 \%)$ & \multirow[t]{2}{*}{0.055} & \multirow[t]{2}{*}{0.815} \\
\hline No & $638(95.2)$ & $428(95.3 \%)$ & $205(94.9 \%)$ & & \\
\hline \multicolumn{6}{|c|}{ Suicidal ideation - past month } \\
\hline Yes & $46(6.9)$ & $27(6.0 \%)$ & $19(8.8 \%)$ & \multirow[t]{2}{*}{1.754} & \multirow[t]{2}{*}{0.185} \\
\hline No & $624(93.1)$ & $422(94.0 \%)$ & $197(91.2 \%)$ & & \\
\hline \multicolumn{6}{|c|}{ Suicidal ideation - past year } \\
\hline Yes & $98(14.7)$ & $60(13.4 \%)$ & $38(17.6 \%)$ & \multirow[t]{2}{*}{2.076} & \multirow[t]{2}{*}{0.150} \\
\hline No & $567(85.3)$ & $389(86.6 \%)$ & $178(82.4 \%)$ & & \\
\hline \multicolumn{6}{|c|}{ Suicidal ideation - lifetime } \\
\hline Yes & $406(61.1)$ & $254(56.6 \%)$ & $152(70.4 \%)$ & \multirow{2}{*}{11.681} & \multirow[t]{2}{*}{$<0.001$} \\
\hline No & $259(38.9)$ & $195(43.4 \%)$ & $64(29.6 \%)$ & & \\
\hline
\end{tabular}

prevalence rate for past-year SI (i.e., 10.6\% compared with $14.7 \%$ in the present study), although the lifetime prevalence was higher in the present study (61.1\% compared with $22.3 \%$ ). Compared with these worldwide prevalence levels, the present study had a much higher lifetime SI rate.

There are many possible reasons for the differences in these prevalence rates including cultural differences as well as socio-demographic and education system differences among the participants surveyed. Based on previous retrospective studies, proximal factors implicated in Bangladeshi student suicides include relationship problems, educational issues such as exam failure, economic problems, and not having a good relationship with parents (Arafat and Mamun 2019; Mamun et al. 2020a, b, c; Mamun and Griffiths 2020a, c). Again, these proximal factors are likely to differ across cultures. Irrespective of the differing prevalence rates, it is estimated that $61 \%$ of the total suicide cases are among those below the age of 30 years in Bangladesh, although the country still lacks appropriate suicide prevention programs (Griffiths et al. 2020; Mamun and Griffiths 2020b; Shah et al. 2017).

In the present study, the past-year SI prevalence rate among participants who were separated or divorced from their partners was approximately five times higher than those who were single and not currently in a relationship. This can be perhaps be explained by the interpersonal theory of suicide (Van Orden et al. 2010), because many the people with relationship problems develop proximal suicide risks such as hopelessness, loneliness, and thwarted belongingness (Dueweke and Schwartz-Mette 2018; Li et al. 2019; Van Orden et al. 2010). Long ago, Durkheim (1951) emphasized the importance of marriage in protecting against suicidality because such individuals are integrated in supportive social networks (Kõlves et al. 2010; Wyder et al. 2009). However, a few authors have claimed that being in a relationship (typically marital status) has little influence on the incremental risk of suicide (e.g., Giddens 2001). In the present study, the group of participants that were separated or divorced from their partner was a small proportion of the total sample (4.2\%), and the findings may simply be a reflection of the strain associated with marital breakdown. Therefore, additional study should be carried out to further examine relationship status and its related factors (e.g., relationship strain) in contributing to suicidality. 
Previously, the association between psychopathology and suicide has been studied globally (Table 4). It has been estimated that more than $90 \%$ of suicides occur due to associated psychiatric suffering (i.e., depression, substance abuse and addiction, anxiety disorders, sleeping disorders, stress). The present study also found that depression, anxiety, and stress were SI risk factors confirming the findings of previous studies (e.g., Dsouza et al. 2020; Fleischmann et al. 2005; Franklin et al. 2017; Harris and Barraclough 1997; Islam et al. 2020; Mamun and Griffiths 2020d, e; Mamun and Ullah 2020). A recent systematic review among 11,557 college students reported that 14 studies (from a total of 29) demonstrated a significant and strong relationship between suicide risk and depression ( $\mathrm{Li}$ et al. 2019). Furthermore, systematic reviews and meta-analyses have examined the relationship between anxiety disorders (e.g., obsessive-compulsive disorder, panic disorder, generalized anxiety disorder, body dysmorphic disorder) and suicidal behaviors (Bentley et al. 2016; Kanwar et al. 2013). It was suggested that individuals with anxiety disorders are approximately three times more likely than those without such disorders to be at risk of suicidal behaviors (Kanwar et al. 2013). However, Bentley and colleagues (Bentley et al. 2016) argued that anxiety played no role in suicide death. Recent review papers have also reported that stress is consistently associated with suicide ideation and attempts (Liu and Miller 2014; Serafini et al. 2015). The number of adversities or negative life events experienced appears to have a positive dose-response association with suicidal behaviors (Cheng et al. 2015).

The present study also reported that higher risk of SI was associated with being at risk for Facebook addiction but not for being at risk of smartphone addiction. It has been established that for the small minority experiencing social media addiction (including Facebook addiction), it is often associated with other psychopathological problems (major depression, bipolar disorder, borderline personality disorder and post-traumatic stress disorders, sleep problems, anxiety disorders) where excessive social media use is used as a coping strategy to alleviate problems the individual may have (Andreassen et al. 2016; Guo et al. 2018; Jasso-Medrano

Table 4 Logistic regression analysis of the variables with past-year suicidal ideation

\begin{tabular}{|c|c|c|c|c|c|c|}
\hline \multirow[t]{2}{*}{ Variables } & \multicolumn{3}{|c|}{ Unadjusted model } & \multicolumn{3}{|l|}{ Adjusted model } \\
\hline & $\begin{array}{l}\text { Odds ratio } \\
(\mathrm{OR})\end{array}$ & $\begin{array}{l}95 \% \text { confidence } \\
\text { interval }(\mathrm{CI})\end{array}$ & $p$ value & $\begin{array}{l}\text { Adjusted odds } \\
\text { ratio (AOR) }\end{array}$ & $\begin{array}{l}95 \% \text { confidence } \\
\text { interval }(\mathrm{CI})\end{array}$ & $p$ value \\
\hline \multicolumn{7}{|l|}{ Relationship status } \\
\hline $\begin{array}{l}\text { Separated/- } \\
\text { divorced }\end{array}$ & 4.486 & $1.972-10.207$ & $<0.001$ & 4.403 & $1.876-10.335$ & $<0.001$ \\
\hline $\begin{array}{l}\text { Single } \\
\text { In a relationship }\end{array}$ & $\begin{array}{l}0.548 \\
\text { Reference }\end{array}$ & $0.343-0.874$ & & $\begin{array}{l}0.586 \\
\text { Reference }\end{array}$ & $0.363-0.947$ & \\
\hline \multicolumn{7}{|c|}{ Social media addiction } \\
\hline $\begin{array}{l}\text { Yes } \\
\text { No }\end{array}$ & $\begin{array}{l}1.550 \\
\text { Reference }\end{array}$ & $1.006-2.388$ & 0.047 & $\begin{array}{l}1.096 \\
\text { Reference }\end{array}$ & $0.686-1.750$ & 0.029 \\
\hline \multicolumn{7}{|l|}{ Depression } \\
\hline $\begin{array}{l}\text { Yes } \\
\text { No }\end{array}$ & $\begin{array}{l}1.657 \\
\text { Reference }\end{array}$ & $1.677-4.211$ & $<0.001$ & $\begin{array}{l}1.679 \\
\text { Reference }\end{array}$ & $0.953-2.957$ & 0.073 \\
\hline \multicolumn{7}{|l|}{ Anxiety } \\
\hline $\begin{array}{l}\text { Yes } \\
\text { No }\end{array}$ & $\begin{array}{l}2.649 \\
\text { Reference }\end{array}$ & $1.624-4.320$ & $<0.001$ & $\begin{array}{l}1.661 \\
\text { Reference }\end{array}$ & $0.915-3.016$ & 0.095 \\
\hline \multicolumn{7}{|l|}{ Stress } \\
\hline $\begin{array}{l}\text { Yes } \\
\text { No }\end{array}$ & $\begin{array}{l}2.626 \\
\text { Reference }\end{array}$ & $1.673-4.122$ & $<0.001$ & $\begin{array}{l}1.449 \\
\text { Reference }\end{array}$ & $0.827-2.539$ & 0.195 \\
\hline
\end{tabular}


and Lopez-Rosales 2018). Such addictions are also associated with an increased incidence of self-harm and suicidal behaviors (Mamun and Griffiths 2019b; Pan and Yeh 2018). This may occur due to poorer self-control and higher levels of impulsivity and risky decision-making. Those addicted to social media may have difficulty in fulfilling their social and academic responsibilities and experience more tension in their lives. Additionally, such individuals tend to adopt avoidant and inflexible coping styles (e.g., suicidal behaviors in extreme cases) when encountering stressful life events (Cheng et al. 2015; Guo et al. 2018).

\section{Limitations}

The present study is limited by its nature of being a cross-sectional study with a modestly sized convenience sample from a single university of Bangladesh. The university from which the participants were sampled from is not necessarily representative of other Bangladeshi universities. Two-thirds of the sample were males which may also have influenced the overall prevalence of suicidal ideation (e.g., if female students are more likely to experience suicidal ideation, then the prevalence rate of suicidal ideation in the present study would be an underestimation). It should also be noted that the study only asked participants "if they had ever thought about suicide". If a different wording had been used (such as "Have you ever seriously thought about killing yourself"), different prevalence rates might have been reported. It should also be noted that the study did not include other variables that could have influenced mental health suffering including various mental and physical health conditions, family history of mental illness or suicide, stressful life events, alcohol or substance use, sexual abuse history, and personality characteristics. Future research is needed using representative student samples and including a wider range of possible variables that might predict suicidal ideation both in and outside of Bangladesh. Ideally such research should be carried out utilizing longitudinal designs to establish causal pathways between the variables examined in the present study.

\section{Conclusions}

Despite these limitations, the study provides novel data on suicidal ideation, in a country where there has been no previous survey study examining student cohorts. The present study found high levels of SI compared with previous studies published in other countries. To protect Bangladeshi university students, special attention is needed. Before considering any awareness and prevention programs, three general aims must be met (i.e., "(i) to enhance awareness regarding suicide among students, (ii) to educate students to recognize possible signs of suicidal behavior for one's own safety and that of others, and (iii) to provide students with information about school and community resources available for aiding" (Shaffer et al. 1988, p.43). The proposed suicide prevention programs should include awareness/education curricula, screening, peer leadership training, skills training, student support centers, and gatekeeper training towards mental health problems and suicide (Arafat and Mamun 2019; Bhuiyan et al. 2020; Cusimano and Sameem 2011; Masud et al. 2020; Katz et al. 2013). Additionally, internet-based interventions such as posting suicide awareness-related information on social 
media sites may be helpful in suicide prevention (Jasso-Medrano and Lopez-Rosales 2018; Luxton et al. 2012).

Acknowledgments The authors would like to thank Nusrat J. Anne for her support during the study implication.

Data Availability Data will be available on request.

\section{Compliance with Ethical Standards}

Conflict of Interest The authors declare that they have no conflict of interest.

Ethical Approval All procedures performed in this study involving human participants were in accordance with the ethical standards of the University's Research Ethics Board and with the 1975 Helsinki Declaration.

Informed Consent Informed consent was obtained from all participants.

Open Access This article is licensed under a Creative Commons Attribution 4.0 International License, which permits use, sharing, adaptation, distribution and reproduction in any medium or format, as long as you give appropriate credit to the original author(s) and the source, provide a link to the Creative Commons licence, and indicate if changes were made. The images or other third party material in this article are included in the article's Creative Commons licence, unless indicated otherwise in a credit line to the material. If material is not included in the article's Creative Commons licence and your intended use is not permitted by statutory regulation or exceeds the permitted use, you will need to obtain permission directly from the copyright holder. To view a copy of this licence, visit http://creativecommons.org/licenses/by/4.0/.

\section{References}

Andreassen, C. S., Torsheim, T., Brunborg, G. S., \& Pallesen, S. (2012). Development of a social media addiction scale. Psychological Reports, 110(2), 501-517.

Andreassen, C. S., Billieux, J., Griffiths, M. D., Kuss, D. J., Demetrovics, Z., Mazzoni, E., \& Pallesen, S. (2016). The relationship between addictive use of social media and video games and symptoms of psychiatric disorders: A large-scale cross-sectional study. Psychology of Addictive Behaviors, 30(2), 252-262.

Arafat, S. M. Y. (2019). Current challenges of suicide and future directions of management in Bangladesh: A systematic review. Global Psychiatry, 2(1), 9-20.

Arafat, S. M. Y., \& Mamun, M. A. A. (2019). Repeated suicides in the University of Dhaka (November 2018): Strategies to identify risky individuals. Asian Journal of Psychiatry, 39, 84-85.

Arafat, S. M. Y., Akter, H., \& Mali, B. (2018). Psychiatric morbidities and risk factors of suicidal ideation among patients attending for psychiatric services at a tertiary teaching hospital in Bangladesh. Asian Journal of Psychiatry, 34, 44- 46.

Bányai, F., Zsila, Á., Király, O., Maraz, A., Elekes, Z., Griffiths, M. D., Andreassen, C. S., \& Demetrovics, Z. (2017). Problematic social media use: Results from a large-scale nationally representative adolescent sample. PloS One, 12(1), e0169839.

Beautrais, A. L. (2000). Risk factors for suicide and attempted suicide among young people. Australian \& New Zealand Journal of Psychiatry, 34(3), 420-436.

Bebbington, P. E., Minot, S., Cooper, C., Dennis, M., Meltzer, H., Jenkins, R., \& Brugha, T. (2010). Suicidal ideation, self-harm and attempted suicide: Results from the British Psychiatric Morbidity Survey 2000. European Psychiatry, 25(7), 427-431.

Becker, K., Mayer, M., Nagenborg, M., El-Faddagh, M., \& Schmidt, M. H. (2004). Parasuicide online: Can suicide websites trigger suicidal behaviour in predisposed adolescents? Nordic Journal of Psychiatry, 58(2), $111-114$.

Begum, A., Rahman, A. K. M. F., Rahman, A., Soares, J., Reza Khankeh, H., \& Macassa, G. (2017). Prevalence of suicide ideation among adolescents and young adults in rural Bangladesh. International Journal of Mental Health, 46(3), 177-187. 
Bentley, K. H., Franklin, J. C., Ribeiro, J. D., Kleiman, E. M., Fox, K. R., \& Nock, M. K. (2016). Anxiety and its disorders as risk factors for suicidal thoughts and behaviors: A meta-analytic review. Clinical Psychology Review, 43, 30-46.

Bhuiyan, M. A. H., Griffiths, M. D., \& Mamun, M. A. (2020). Depression literacy among Bangladeshi preuniversity students: Differences based on gender, educational attainment, depression, and anxiety. Asian Journal of Psychiatry, 50, e101944.

Blasco, M. J., Vilagut, G., Almenara, J., Roca, M., Piqueras, J. A., Gabilondo, A., et al. (2019). Suicidal thoughts and behaviors: Prevalence and association with distal and proximal factors in Spanish university students. Suicide and Life-threatening Behavior, 49(3), 881-898.

Chen, I.-H., Strong, C., Lin, Y.-C., Tsai, M.-C., Leung, H., Lin, C.-Y., et al. (2019). Time invariance of three ultra-brief internet-related instruments: Smartphone Application-Based Addiction Scale (SABAS), Bergen Social Media Addiction Scale (BSMAS), and the nine-item Internet Gaming Disorder Scale-Short Form (IGDS-SF9)(study part B). Addictive Behaviors, 101, 105960.

Cheng, C., Sun, P., \& Mak, K.-K. (2015). Internet addiction and psychosocial maladjustment: Avoidant coping and coping inflexibility as psychological mechanisms. Cyberpsychology, Behavior and Social Networking, 18(9), 539-546.

Csibi, S., Griffiths, M. D., Cook, B., Demetrovics, Z., \& Szabo, A. (2018). The psychometric properties of the Smartphone Application-Based Addiction Scale (SABAS). International Journal of Mental Health and Addiction, 16(2), 393-403.

Cusimano, M. D., \& Sameem, M. (2011). The effectiveness of middle and high school-based suicide prevention programmes for adolescents: A systematic review. Injury Prevention, 17(1), 43-49.

Dsouza, D. D., Quadros, S., Hyderabadwala, Z. J., \& Mamun, M. A. (2020). Aggregated COVID-19 suicide incidences in India: Fear of COVID-19 infection is the prominent causative factor. Psychiatry Research, 290, e113145

Dueweke, A. R., \& Schwartz-Mette, R. A. (2018). Social-cognitive and social-behavioral correlates of suicide risk in college students: Contributions from interpersonal theories of suicide and depression. Archives of Suicide Research, 22(2), 224-240.

Durkheim, E. (1951). Suicide: a study in sociology (J. A. Spaulding \& G. Simpson, trans.). Glencoe, IL: Free Press.

Eaton, D. K., Foti, K., Brener, N. D., Crosby, A. E., Flores, G., \& Kann, L. (2011). Associations between risk behaviors and suicidal ideation and suicide attempts: Do racial/ethnic variations in associations account for increased risk of suicidal behaviors among Hispanic/Latina 9th-to 12th-grade female students? Archives of Suicide Research, 15(2), 113-126.

Eskin, M., Sun, J.-M., Abuidhail, J., Yoshimasu, K., Kujan, O., Janghorbani, M., et al. (2016). Suicidal behavior and psychological distress in university students: A 12-nation study. Archives of Suicide Research, 20(3), 369-388.

Feroz, A. H. M., Islam, S. M. N., Reza, S., Rahman, A. K. M. M., Sen, J., Mowla, M., \& Rahman, M. R. (2012). A community survey on the prevalence of suicidal attempts and deaths in a selected rural area of Bangladesh. Journal of Medicine, 13(1), 3-9.

Fleischmann, A., Bertolote, J. M., Belfer, M., \& Beautrais, A. (2005). Completed suicide and psychiatric diagnoses in young people: A critical examination of the evidence. American Journal of Orthopsychiatry, 75(4), 676-683.

Franklin, J. C., Ribeiro, J. D., Fox, K. R., Bentley, K. H., Kleiman, E. M., Huang, X., Musacchio, K. M., Jaroszewski, A. C., Chang, B. P., \& Nock, M. K. (2017). Risk factors for suicidal thoughts and behaviors: A meta-analysis of 50 years of research. Psychological Bulletin, 143(2), 187-232.

Giddens, A. (2001). Sociology (4th ed.). Cambridge, UK: Polity Press.

Griffiths, M. D., Misti, J. M., \& Mamun, M. A. (2020). Bangladeshi medical students' suicide: A response to Arafat (2020). Asian Journal of Psychiatry, 53, e102201.

Guo, L., Luo, M., Wang, W.-X., Huang, G.-L., Xu, Y., Gao, X., Lu, C. Y., \& Zhang, W.-H. (2018). Association between problematic internet use, sleep disturbance, and suicidal behavior in Chinese adolescents. Journal of Behavioral Addictions, 7(4), 965-975.

Harris, E. C., \& Barraclough, B. (1997). Suicide as an outcome for mental disorders. A meta-analysis. British Journal of Psychiatry, 170(3), 205-228.

Islam, S. M. D., Bodrud-Doza, M., Khan, R. M., Haque, M. A., \& Mamun, M. A. (2020). Exploring COVID-19 stress and its factors in Bangladesh: A perceptionbased study. Heliyon, 6, e04399. https://doi.org/10.1016/j. heliyon.2020.e04399.

Jahan, S., Araf, K., Gozal, D., Griffiths, M. D., \& Mamun, M. A. (2020). Depression and suicidal behaviors among Bangladeshi mothers of children with Autism Spectrum Disorder: A comparative study. Asian Journal of Psychiatry, 51, e101994. 
Jasso-Medrano, J. L., \& Lopez-Rosales, F. (2018). Measuring the relationship between social media use and addictive behavior and depression and suicide ideation among university students. Computers in Human Behavior, 87, 183-191.

Kanwar, A., Malik, S., Prokop, L. J., Sim, L. A., Feldstein, D., Wang, Z., \& Murad, M. H. (2013). The association between anxiety disorders and suicidal behaviors: A systematic review and meta-analysis. Depression and Anxiety, 30(10), 917-929.

Katz, C., Bolton, S., Katz, L. Y., Isaak, C., Tilston-Jones, T., Sareen, J., \& Team, S. C. S. P. (2013). A systematic review of school-based suicide prevention programs. Depression and Anxiety, 30(10), 1030-1045.

Kim, M.-H., Min, S., Ahn, J.-S., An, C., \& Lee, J. (2019). Association between high adolescent smartphone use and academic impairment, conflicts with family members or friends, and suicide attempts. PloS One, 14(7), e0219831.

Klonsky, E. D., May, A. M., \& Saffer, B. Y. (2016). Suicide, suicide attempts, and suicidal ideation. Annual Review of Clinical Psychology, 12, 307-330.

Kõlves, K., Ide, N., \& De Leo, D. (2010). Suicidal ideation and behaviour in the aftermath of marital separation: Gender differences. Journal of Affective Disorders, 120(1-3), 48-53.

Li, W., Dorstyn, D. S., \& Jarmon, E. (2019). Identifying suicide risk among college students: A systematic review. Death Studies, 44, 450-458.

Lin, C.-Y., Imani, V., Broström, A., Nilsen, P., Fung, X. C. C., Griffiths, M. D., \& Pakpour, A. H. (2019). Smartphone application-based addiction among Iranian adolescents: A psychometric study. International Journal of Mental Health and Addiction, 17(4), 765-780.

Liu, R. T., \& Miller, I. (2014). Life events and suicidal ideation and behavior: A systematic review. Clinical Psychology Review, 34(3), 181-192.

Lovibond, P. F., \& Lovibond, S. H. (1995). Manual for the Depression Anxiety Stress Scales (2nd ed.). Sydney: Pscyhology Foundation.

Luxton, D. D., June, J. D., \& Fairall, J. M. (2012). Social media and suicide: A public health perspective. American Journal of Public Health, 102(S2), S195-S200.

Mamun, M. A. A., \& Griffiths, M. D. (2019a). The association between Facebook addiction and depression: A pilot survey study among Bangladeshi students. Psychiatry Research, 271, 628-633.

Mamun, M. A., \& Griffiths, M. D. (2019b). The psychosocial impact of extreme gaming on Indian PUBG gamers: The case of PUBG (PlayerUnknown's Battlegrounds). International Journal of Mental Health and Addiction. Advanced online publication https://doi.org/10.1007/s11469-019-00102-4.

Mamun, M. A., \& Griffiths, M. D. (2020a). Young teenage suicides in Bangladesh-Are mandatory junior school certificate exams to blame? International Journal of Mental Health and Addiction. https:/doi. org/10.1007/s11469-020-00275-3.

Mamun, M. A., \& Griffiths, M. D. (2020b). Mandatory Junior School Certificate exams and young teenage suicides in Bangladesh: A response to Arafat (2020). International Journal of Mental Health and Addiction, Advanced online publication. https://doi.org/10.1007/s11469-020-00324-x.

Mamun, M. A., \& Griffiths, M. D. (2020c). A rare case of Bangladeshi student suicide by gunshot due to unusual multiple causalities. Asian Journal of Psychiatry, 49, e101951.

Mamun, M. A., \& Griffiths, M. D. (2020d). PTSD-related suicide six years after the Rana Plaza collapse in Bangladesh. Psychiatry Research, 287, e112645.

Mamun, M. A., \& Griffiths, M. D. (2020e). First COVID-19 suicide case in Bangladesh due to fear of COVID19 and xenophobia: Possible suicide prevention strategies. Asian Journal of Psychiatry, 51, e102073.

Mamun, M. A., \& Ullah, I. (2020). COVID-19 suicides in Pakistan, dying off not COVID-19 fear but poverty? The forthcoming economic challenges for a developing country. Brain, Behavior, and Immunity, 87, 163166.

Mamun, M. A., Hossain, M. S., Siddique, A. B., Sikder, M. T., Kuss, D. J., \& Griffiths, M. D. (2019a). Problematic internet use in Bangladeshi students: The role of socio-demographic factors, depression, anxiety, and stress. Asian Journal of Psychiatry, 44, 48-54.

Mamun, M. A., Rafi, M. A., Al Mamun, A. S., Hasan, M. Z., Akter, K., Hsan, K., \& Griffiths, M. D. (2019b). Prevalence and psychiatric risk factors of excessive internet use among northern Bangladeshi job-seeking graduate students: A pilot study. International Journal of Mental Health and Addiction. https://doi. org/10.1007/s11469-019-00066-5.

Mamun, M. A., Misti, J. M., \& Griffiths, M. D. (2020a). Suicide of Bangladeshi medical students: Risk factor trends based on Bangladeshi press reports. Asian Journal of Psychiatry, 48, 101905.

Mamun, M. A., Siddique, A. B., Sikder, M. T., \& Griffiths, M. D. (2020b). Student suicide risk and gender: A retrospective study from Bangladeshi press reports. International Journal of Mental Health and Addiction. https://doi.org/10.1007/s11469-020-00267-3. 
Mamun, M. A., Chandrima, R. M., \& Griffiths, M. D. (2020c). Mother and son suicide pact due to COVID-19related online learning issues in Bangladesh: An unusual case report. International Journal of Mental Health and Addiction. https://doi.org/10.1007/s11469-020-00362-5.

Mashreky, S. R., Rahman, F., \& Rahman, A. (2013). Suicide kills more than 10,000 people every year in Bangladesh. Archives of Suicide Research, 17(4), 387-396.

Masud, M. T., Mamun, M. A., Thapa, K., Lee, D. H., Griffiths, M. D., \& Yang, S. H. (2020). Unobtrusive monitoring of behavior and movement patterns to detect clinical depression severity level via smartphone. Journal of Biomedical Informatics, 103, e103371.

McKinnon, B., Gariépy, G., Sentenac, M., \& Elgar, F. J. (2016). Adolescent suicidal behaviours in 32 low-and middle-income countries. Bulletin of the World Health Organization, 94(5), 340-350F.

Mok, K., Jorm, A. F., \& Pirkis, J. (2015). Suicide-related Internet use: A review. Australian \& New Zealand Journal of Psychiatry, 49(8), 697-705.

Mortier, P., Cuijpers, P., Kiekens, G., Auerbach, R. P., Demyttenaere, K., Green, J. G., Kessler, R. C., Nock, M. K., \& Bruffaerts, R. (2018). The prevalence of suicidal thoughts and behaviours among college students: A meta-analysis. Psychological Medicine, 48(4), 554-565.

Pan, P.-Y., \& Yeh, C.-B. (2018). Internet addiction among adolescents may predict self-harm/suicidal behavior: A prospective study. Journal of Pediatrics, 197, 262-267.

Peltzer, K., Yi, S., \& Pengpid, S. (2017). Suicidal behaviors and associated factors among university students in six countries in the Association of Southeast Asian Nations (ASEAN). Asian Journal of Psychiatry, 26, 3238.

Rafi, M. A., Mamun, M. A., Hsan, K., Hossain, M., \& Gozal, D. (2019). Psychological implications of unemployment among Bangladesh Civil Service job seekers: A pilot study. Frontiers in Psychiatry, $10,578$.

Salam, S. S., Alonge, O., Islam, M., Hoque, D., Wadhwaniya, S., U1 Baset, M., et al. (2017). The burden of suicide in rural Bangladesh: Magnitude and risk factors. International Journal of Environmental Research and Public Health, 14(9), e1032.

Serafini, G., Muzio, C., Piccinini, G., Flouri, E., Ferrigno, G., Pompili, M., Girardi, P., \& Amore, M. (2015). Life adversities and suicidal behavior in young individuals: A systematic review. European Child \& Adolescent Psychiatry, 24(12), 1423-1446.

Shaffer, D., Garland, A., Gould, M., Fisher, P., \& Trautman, P. (1988). Preventing teenage suicide: A critical review. Journal of the American Academy of Child \& Adolescent Psychiatry, 27(6), 675-687.

Shah, M. M. A., Ahmed, S., \& Arafat, S. M. Y. (2017). Demography and risk factors of suicide in Bangladesh: A six-month paper content analysis. Psychiatry Journal, 3047025.

Turecki, G., \& Brent, D. A. (2016). Suicide and suicidal behaviour. The Lancet, 387(10024), 1227-1239.

Van Orden, K. A., Witte, T. K., Cukrowicz, K. C., Braithwaite, S. R., Selby, E. A., \& Joiner Jr., T. E. (2010). The interpersonal theory of suicide. Psychological Review, 117(2), 575-600.

World Health Organization (2019). Suicide - Key facts. Retrieved October 7, 2020, from: https://www.who. int/news-room/fact-sheets/detail/suicide.

Wong, P. W.-C., Fu, K.-W., Yau, R. S.-P., Ma, H. H.-M., Law, Y.-W., Chang, S.-S., \& Yip, P. S.-F. (2013). Accessing suicide-related information on the internet: A retrospective observational study of search behavior. Journal of Medical Internet Research, 15(1), e3.

Wyder, M., Ward, P., \& De Leo, D. (2009). Separation as a suicide risk factor. Journal of Affective Disorders, $116(3), 208-213$.

Publisher's Note Springer Nature remains neutral with regard to jurisdictional claims in published maps and institutional affiliations. 


\section{Affiliations}

\section{Mohammed A. Mamun ${ }^{1,2} \cdot$ Istihak Rayhan ${ }^{3} \cdot$ Khaleda Akter $^{4} \cdot$ Mark D. Griffiths $^{5}$}

Mohammed A. Mamun

mamunphi46@gmail.com

Istihak Rayhan

istihakshuvo@gmail.com

Khaleda Akter

khaleda.nur.econju@gmail.com

1 Undergraduate Research Organization, Savar, Dhaka, Bangladesh

2 Department of Public Health and Informatics, Jahangirnagar University, Savar, Dhaka, Bangladesh

3 Department of Economics, Bangabandhu Sheikh Mujibur Rahman Science and Technology University, Gopalganj, Bangladesh

4 Department of Economics, Pabna University of Science and Technology, Pabna, Bangladesh

5 Psychology Department, Nottingham Trent University, 50 Shakespeare Street, Nottingham NG1 4FQ, UK 